This is the peer reviewed version of the following article: "Nucleophilic Trifluoromethylation Reactions Involving Copper(I) Species: From Organometallic Insights to Scope" which has been published in final form at:

https://www.thieme-connect.com/products/ejournals/abstract/10.1055/s-0037-1611776

This article may be used for non-commercial purposes in accordance with Thieme Terms and Conditions for Self-Archiving

\title{
Nucleophilic Trifluoromethylation Reactions Involving Copper(I) Species: From Organometallic Insights to Scope
}

\author{
Ángel L. Mudarrata,b \\ Sara Martínez de Salinas ${ }^{\text {ta }}$ \\ Mónica H. Pérez-Temprano*a \\ ${ }^{a}$ Institute of Chemical Research of Catalonia (ICIQ) Avgda. \\ Països Catalans, 16, 43007 Tarragona (Spain) \\ ${ }^{\mathrm{b}}$ Department de Química Analítica I Química Orgànica, \\ Universitat Rovira i Virgili, C/Marcelli Domingo s/n, 43007 \\ Tarragona (Spain) \\ ${ }^{\dagger}$ These authors contributed equally to this work. \\ mperez@iciq.es \\ Click here to insert a dedication
}

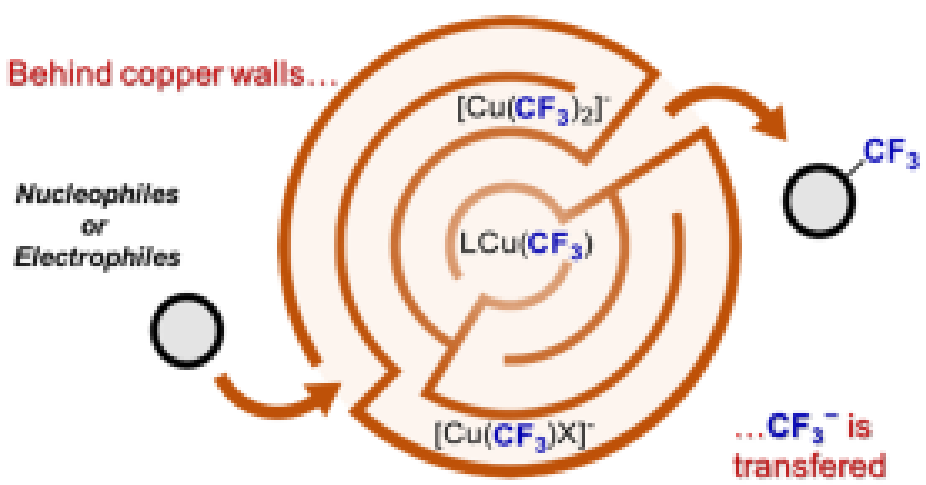

\section{Received
Accepted:}

Published online:

Abstract Over the last decades, trifluoromethyl copper(I) complexes have played a key role as reactive species in the formation of $\mathrm{C}_{-}-\mathrm{CF}_{3}$ bond-forming reactions. This Short Review covers not only select examples of relevant $\mathrm{Cu}$ mediated or catalyzed nucleophilic trifluoromethylation reactions, one of the most active fields in organic synthesis, but also provides a comprehensive picture of the real behavior of these copper species, including ubiquitous cuprates, in the reaction media.

Introduction

Historical perspective of the identification of relevant trifluoromethyl copper(I) species

In-situ generation of active trifluoromethyl copper(I) species

Well defined active trifluoromethyl copper(I) complexes

Recent advances on the reactivity of different trifluoromethylation

protocols

$6 \quad$ Conclusions

Key words trifluoromethylation, copper, ate-type complexes, catalysis, organometallic chemistry
The trifluoromethyl group is a prevalent motif in pharmaceuticals, agrochemicals and materials due to its unique capability to change physical, chemical and biological properties of organic molecules. ${ }^{1}$ Thus, over the past years, the scientific community has directed its efforts towards the development of rapid and efficient strategies to install this privileged functional group onto organic scaffolds. ${ }^{2}$ In this context, a tremendous success has been achieved by using copper as mediator. Back in the 60s, McLoughlin and Thrower reported a pioneering work that allowed, for the first time, the perfluoroalkylation of haloarenes involving $\mathrm{Cu}-\mathrm{R}_{\mathrm{f}}$ species. ${ }^{3}$ Since then, different types of trifluoromethyl copper organometallic complexes, ranging from in-situ generated "CuCF 3 " species to well-defined $\mathrm{Cu}(\mathrm{I})$ trifluoromethyl complexes, have been proposed to play a key role as intermediates in $\mathrm{C}-\mathrm{CF}_{3}$ bond-forming reactions. ${ }^{2 \mathrm{~b}, \mathrm{e}, \mathrm{g}, 4}$ 


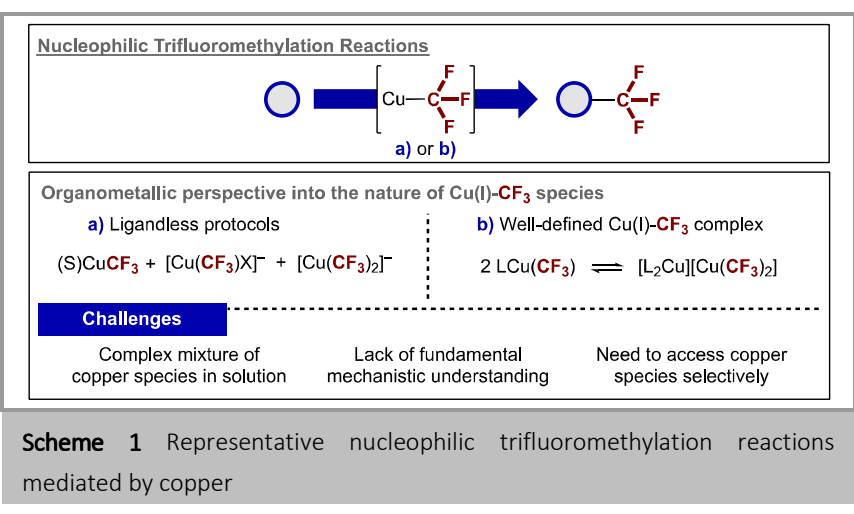

This Short Review not only revisits selected and relevant examples of nucleophilic trifluoromethylation reactions involving trifluoromethyl copper(I) species but also gives an organometallic perspective of overlooked aspects related to these transformations where, in general, there is a lack of fundamental understanding (Scheme 1). This is likely to the potential involvement of different copper species as reaction intermediates, including neutral and ionic complexes, (cat) $\left[\mathrm{Cu}\left(\mathrm{CF}_{3}\right) \mathrm{X}\right], \mathrm{X}=$ halogen or $\mathrm{CF}_{3}$, whose characterization is far from being trivial.4a-e In this regard, the real role of cuprates, ubiquitous in $\mathrm{Cu}$-mediated nucleophilic trifluoromethylations, remains practically unexplored, due to the challenges associated to their selective access in solution. Moreover, the scarce piece of information about them is disseminated among the literature and, sometime, shallowly mentioned. For this reason, we decided to focus our attention on both the preparation and the synthetic utility of the so-called "ligandless" in-situ generated $\left[\mathrm{CuCF}_{3}\right]$ and the well-defined trifluoromethyl copper(I) complexes specially when the cuprates are explicitly mentioned. From our point of view, these often-neglected cuprates could potentially be noninnocent spectators in the reaction and therefore, we will end up this Short Review by discussing our recent contributions into this field. 5

\section{Historical Perspective of the identification of relevant trifluoromethyl copper(I) species}

As mentioned above, one of the main challenges associated to $\mathrm{Cu}$ catalyzed or mediated nucleophilic trifluoromethylation reactions is the characterization of the copper species present in solution. In order to facilitate reading comprehension, we decided to start this Short Review covering, in chronological order, the literature precedents focused on the identification of the different trifluoromethyl copper species relevant for these transformations (Scheme 2)

In 1986, Burton et al. described for the first time that the in-situformed mixture of "ligandless" $\left[\mathrm{CuCF}_{3}\right]$ contained elusive and complex species whose characterization was non-trivial. ${ }^{6}$ Initially, the authors observed a "ligandless" $\mathrm{CuCF}_{3}$ species $(\delta=-$ $28.8 \mathrm{ppm}$ ) by ${ }^{19} \mathrm{~F}$ NMR spectroscopy when they performed the reaction between $\mathrm{CuBr}$ and $\mathrm{CF}_{3} \mathrm{CdX}$ in $\mathrm{DMF}$ at $-50{ }^{\circ} \mathrm{C}$ However, when the solution was warmed up, two new species were detected $(\delta=-32.3$ and $-35.5 \mathrm{ppm})$. These three " $\mathrm{CuCF}_{3}$ " species show remarkably different reactivity towards air-oxidation, trifluoromethylation and hydrolysis. In 1989, the same research group performed further studies in order to provide a better understanding of the nature of the copper species involved in the "ligandless" $\left[\mathrm{CuCF}_{3}\right] .7$ This was the first time that species such as $(\mathrm{CdI})\left[\mathrm{Cu}\left(\mathrm{CF}_{3}\right)_{2}\right]$ or $(\mathrm{Cd})\left[\mathrm{Cu}\left(\mathrm{CF}_{3}\right) \mathrm{I}\right]$ (named in the paper as $\mathrm{CuCF}_{3} \cdot \mathrm{L}$ $\mathrm{L}=$ metal halide) was proposed to be part of the "ligandless" $\left[\mathrm{CuCF}_{3}\right]$. However, it was not until 2008, when Kolomitsev et al. confirmed that the term "ligandless" $\left[\mathrm{CuCF}_{3}\right]$ was an oversimplification. During the in-situ generation of $\left[\mathrm{CuCF}_{3}\right]$ by reaction of $\mathrm{CuBr}, \mathrm{KF}$ and $\mathrm{Me}_{3} \mathrm{SiCF}_{3}$ in $\mathrm{DMF} / \mathrm{DMI}$ as solvent at $0{ }^{\circ} \mathrm{C}$ they observed that copper was speciated in three different complexes: $\mathrm{CuCF}_{3}$-solvent, $\left[\mathrm{Cu}\left(\mathrm{CF}_{3}\right)_{2}\right]^{-}$and $\left[\mathrm{Cu}\left(\mathrm{CF}_{3}\right)_{4}\right]^{-}$exhibiting three singlets in the ${ }^{19} \mathrm{~F}$ NMR spectrum: $-28.8 \mathrm{ppm} ;-32.3 \mathrm{ppm}$ and $-35.5 \mathrm{ppm}$, respectively. Further investigations revealed that

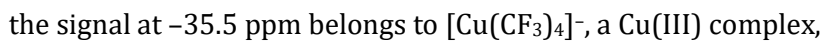
inert towards the activation of aryl halides. ${ }^{8}$

In 1988, Parker and co-workers reported the aromatic trifluoromethylation via decarboxylation of sodium trifluoromethyl carboxylates. In this work, the authors performed mechanistic studies that pointed out the intermediacy of a nucleophilic species, that they assigned as a heteroleptic cuprate $\left[\mathrm{Cu}\left(\mathrm{CF}_{3}\right) \mathrm{I}\right]^{-.9}$ A year later, the same heteroleptic cuprate was proposed to be involved in the trifluoromethylation of aryl, alkenyl and alkyl halides when using $\mathrm{CuI}$ and a new trifluoromethyl source, methyl fluorosulphonyldifluoroacetate. ${ }^{10}$ However, the first time that this specie was characterized by ${ }^{19} \mathrm{~F}$ NMR was in 2011, by Goossen et al., [Cu(CF $) \mathrm{I}]^{-}(\delta=-28.14 \mathrm{ppm})$. 11

The observation of multiple copper species is not only found in the in-situ synthetic routes but also when using the well-defined complexes. In these cases, it has been observed that the neutral $\mathrm{LCu}\left(\mathrm{CF}_{3}\right)(\mathrm{L}=\mathrm{SIMes}$, phenanthroline $)$ are in dynamic equilibrium with the corresponding cuprate $\left(\mathrm{L}_{2} \mathrm{Cu}\right)\left[\mathrm{Cu}\left(\mathrm{CF}_{3}\right)_{2}\right]$, which are inevitablely part of the synthesized "trifluoromethylating agent". 4 c-e 


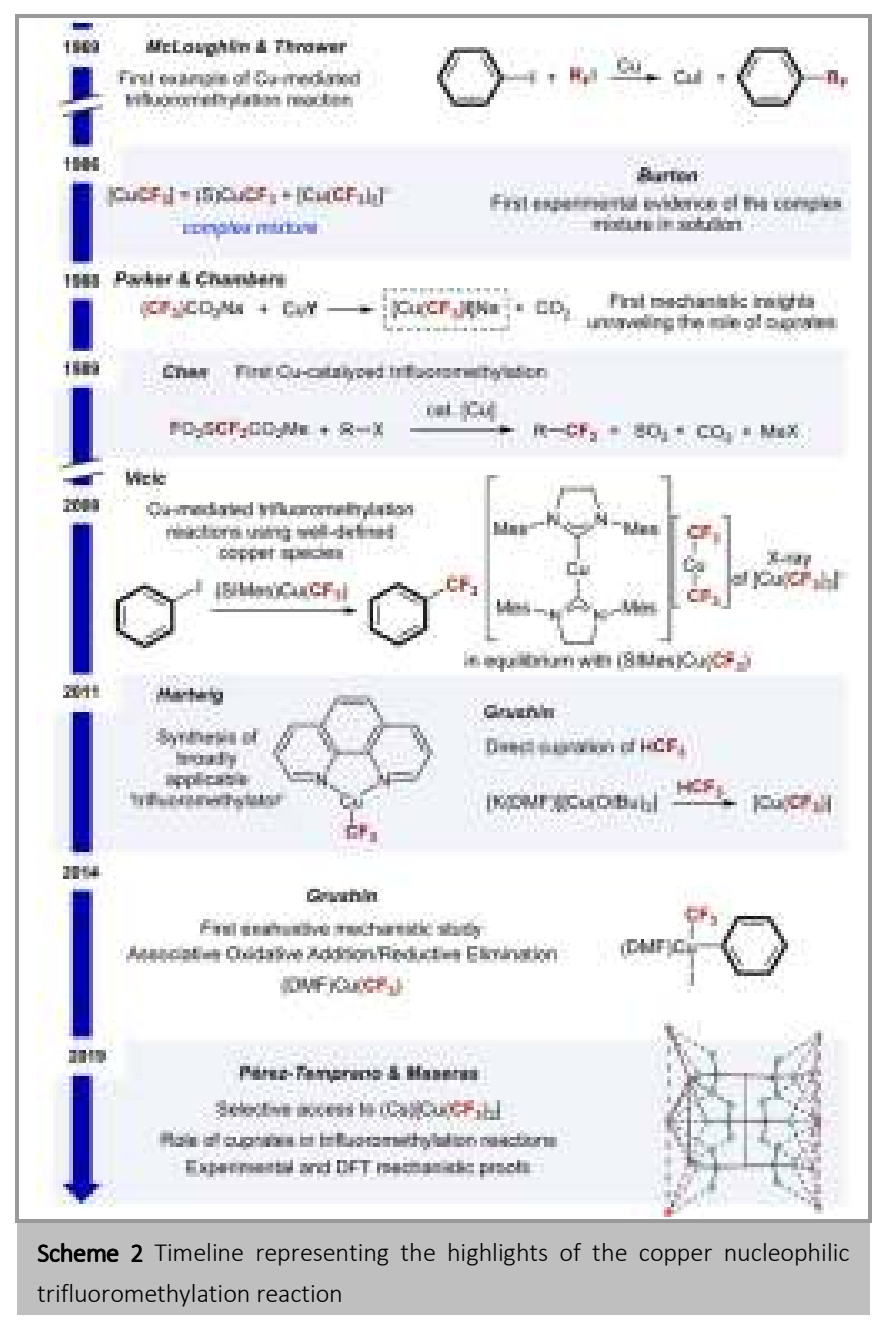

3

\section{In-situ generation of active trifluoromethyl copper(I) species}

In this section, we will describe selected examples of synthetic routes for accessing in-situ generated trifluoromethyl copper(I) species and their applications in the synthesis of trifluoromethylated organic scaffolds (Scheme 3). We have organized this section based on the nature of the source that provides the nucleophilic $\mathrm{CF}_{3}$ reagent to the copper: (i) fluoroform; (ii) trifluoromethylated organic sources as nucleophilic $\mathrm{CF}_{3}$ synthons and (iii) other trifluoromethyl organometallic complexes that act as $\mathrm{CF}_{3}$ shuttle through a transmetalation step. It should be highlighted that the commonly named $\left[\mathrm{CuCF}_{3}\right]$ refers to the complex mixture of copper species described above, which includes the presence of cuprates.

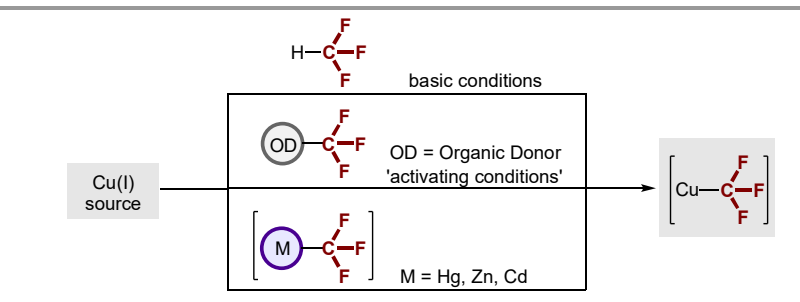

Scheme 3 Procedures to generate in-situ $\left[\mathrm{CuCF}_{3}\right]$

\subsection{Fluoroform as synthetic equivalent of $\mathrm{CF}_{3}{ }^{-}$}

Fluoroform is the ideal synthetic equivalent of the $\mathrm{CF}_{3}{ }^{-}$synthon. It is cheap, readily available and a side product of the synthesis of Teflon ${ }^{\circledR}$ which makes its use even more interesting. Furthermore, fluoroform is a weak acid that can be deprotonated by strong bases. ${ }^{12}$ The first time that $\mathrm{HCF}_{3}$ was utilized in the preparation of $\left[\mathrm{CuCF}_{3}\right]$ was reported in 2000 , by Folléas and co-workers. ${ }^{13}$ They described the in-situ synthesis of the potassium trifluoromethylated aminoalcoholate $(\mathrm{K})\left[\mathrm{Me}_{2} \mathrm{NCH}(0) \mathrm{CF}_{3}\right]$ using $\mathrm{CF}_{3} \mathrm{H}$ and Dimsyl-K (potassium methylsulfinylmethylide) in DMF at $-40^{\circ} \mathrm{C}$. This aminoalcoholate reacted with copper iodide and a stabilizing reagent such as DMEU (Dimethylol ethylene urea) to give rise a new tetrahedral intermediate that evolved at room temperature into $\left[\mathrm{CuCF}_{3}\right](47 \%)$ and $N, N$-dimethylformamide (Scheme 4a). The transference of the $\mathrm{CF}_{3}$ in the copper trifluoromethyl aminoalcoholate is crucial for the reaction to proceed as described in a tentative mechanism shown in Scheme $4 \mathrm{~b}$. They observed by ${ }^{19} \mathrm{~F}$ NMR spectroscopy two different species: : $\delta=-25 \mathrm{ppm}$, presumably (DMF) $\mathrm{CuCF}_{3}$ and $\delta=-30 \mathrm{ppm}$ $\left[\mathrm{Cu}\left(\mathrm{CF}_{3}\right) \mathrm{I}\right]^{-}$and both could be involved in the formation of the trifluoromethylated product.

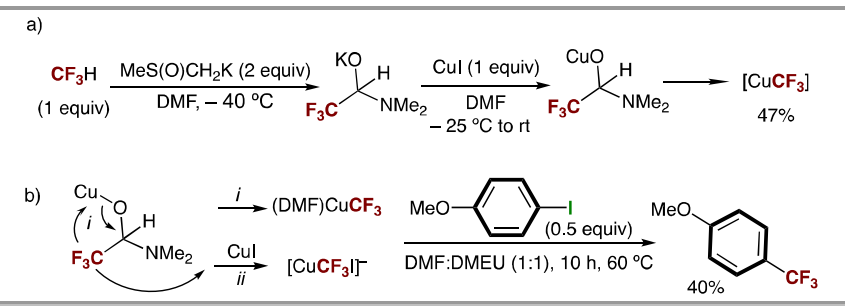

Scheme 4 a) Formation of [ $\mathrm{CuCF}_{3}$ ] using $\mathrm{HCF}_{3}$ and Dimsyl-K (See Ref. 13 for further details). b) Proposed species in the reaction media during the trifluoromethylation reaction

In 2011, Grushin et al. disclosed the direct cupration of fluoroform. This involves the formation of trifluoromethyl copper(I) complex using $\mathrm{HCF}_{3}$ without the necessity of organic intermediates. This groundbreaking synthesis was achieved by using a novel ate-type complex, $[\mathrm{K}(\mathrm{DMF})]\left[\mathrm{Cu}\left(\mathrm{O}^{\mathrm{t}} \mathrm{Bu}\right)_{2}\right]$, that instantaneously reacts with $\mathrm{HCF}_{3}$ to yield $\left[\mathrm{CuCF}_{3}\right]$ almost quantitatively. $4 \mathrm{f}, 14$ This complex is stable at $-35^{\circ} \mathrm{C}$ for days after treatment with $\mathrm{Et}_{3} \mathrm{~N} \cdot 3 \mathrm{HF}$, affording solutions of $\left[\mathrm{CuCF}_{3}\right](95 \%$ yield) as a mixture of (DMF)CuCF $3(85 \%)$ and $\left[\mathrm{Cu}\left(\mathrm{CF}_{3}\right)_{2}\right]^{-}(10 \%)$ by ${ }^{19} \mathrm{~F}$ NMR analysis (Scheme 5). This solution could be used in the trifluoromethylation of organometallic species, affording (IPr) $\mathrm{CuCF}_{3}$ or [(TMEDA)Pd(Ph) $\mathrm{CF}_{3}$ ], and organic electrophiles. In this regard, the authors were able to functionalize methyl iodide, different aryl iodides, bearing electron-donating and withdrawing substituents, and selected heteroaryl iodides. 


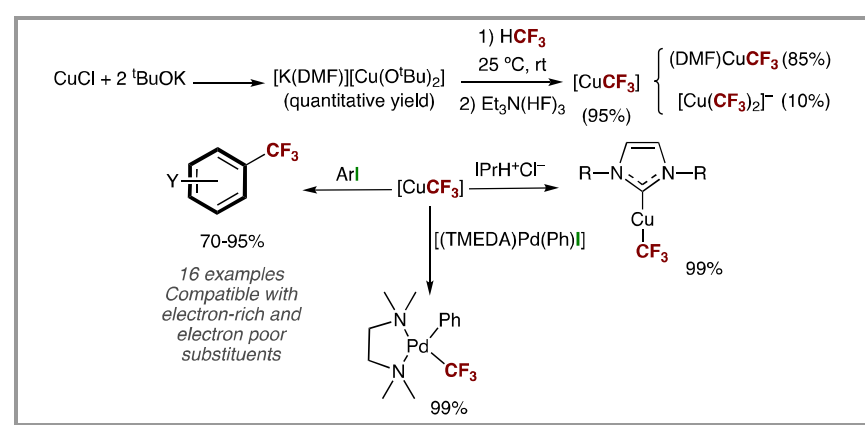

Scheme 5 Cupration of fluoroform and representative examples of its applicability (see Ref. $4 \mathrm{f}$ and 14 for further details)

In 2014, the same research group performed an exhaustive experimental and computational study, in order to unravel the mechanism of the nucleophilic $\mathrm{Cu}$-mediated trifluoromethylation using (DMF)CuCF 3 as model system. ${ }^{4 i}$ Up until that date, only scarce mechanistic hints could be found in the literature: i) the common rate trend when using different aryl halides (Ar-I > Ar$\mathrm{Br}>\mathrm{Ar}-\mathrm{Cl}$ ); ii) the prevalent employment of DMF as solvent and iii) the use of radical clock experiments that discarded a radical mechanism $^{4 c}$. In this venue, Grushin provided relevant information to the field. The most likely scenario involved an associative oxidative addition $(\mathrm{OA})$, which is the rate determining step, of the aryl halide to the (DMF) $\mathrm{CuCF}_{3}$ complex and, subsequently, the reductive elimination (RE) from the $\mathrm{Cu}(\mathrm{III})$ intermediate. This proposal is supported by the Hammett plot correlation $\left(\sigma_{\mathrm{p}}, \rho\right.$ positive) and DFT calculations, which agreed with the experimental activation parameters $\left(\Delta \mathrm{G}^{\ddagger} \exp \approx 24\right.$ $\mathrm{kcal} / \mathrm{mol}$ vs $\Delta \mathrm{G}^{\ddagger}{ }_{\mathrm{DFT}}=21.9 \mathrm{kcal} / \mathrm{mol}$ ). Moreover, the ortho effect was also investigated. Two parameters were found to be important in the performance of the reaction with ortho substitution pattern: the coordination of the substituent to the copper center, which facilitates the oxidative addition transition state, and the destabilization of the organic substrate by the ortho-substituent respect to their para isomers. The same correlation was found in coinage metal-mediated decarboxylation reactions. ${ }^{15}$

Further computational investigations were performed to evaluate other potential active species in the trifluoromethylation. The oxidative addition of the substrate towards $\left[\mathrm{Cu}\left(\mathrm{CF}_{3}\right)_{2}\right]^{-}$or $\left[\mathrm{Cu}\left(\mathrm{CF}_{3}\right) \mathrm{I}\right]^{-}$are less prompted to take place. However, this computational data was not supported by experimental evidences and little was known at that time about the potential reactivity of these cuprates due to the lack of a selective synthetic route for accessing them (see Section 5).

\subsection{Trifluoromethyl organic sources of nucleophilic trifluoromethyl synthon}

The use of trifluoroacetic acid derivatives as $\mathrm{CF}_{3}$ source for accessing trifluoromethyl copper(I) species has been widely studied due to their availability and convenience (Scheme 6) . In this regard, Kondo and co-workers applied this synthetic route for the first time in the decarboxylative trifluoromethylation reaction of aryl iodides by combining sodium trifluoroacetate and CuI.9a Later, in 1988, Chambers et al. expanded this methodology to aryl bromides, heteroaryl iodides and vinyl bromides. $^{9 \mathrm{~b}}$ Interestingly, in this work they proposed the likely intermediacy of $\left[\mathrm{Cu}\left(\mathrm{CF}_{3}\right) \mathrm{I}\right]$ - since Hammett plot studies pointed out the nucleophilic character of the active species. Although, these pioneering works have inspired the use of other trifluoromethylated acetates, in all the cases harsh conditions are required to decarboxylate the corresponding salt. ${ }^{16}$ The commonly accepted mechanistic scenario involves the formation of nucleophilic $\left[\mathrm{CuCF}_{3}\right]$ as reactive intermediates. ${ }^{17}$

\begin{tabular}{|c|c|c|c|c|}
\hline \multirow{2}{*}{$\begin{array}{l}\text { Kondo, } 1981 \\
\mathrm{CF}_{3} \mathrm{CO}_{2} \mathrm{Na}\end{array}$} & Cul, NMP, $160^{\circ} \mathrm{C}$ & & Cul, KO'Bu, DMF & \multirow{2}{*}{$\begin{array}{c}\text { Prakash, } 2003 \\
-\mathrm{PhSO}_{2} \mathrm{CF}_{3} \\
\text { Mikami, } 2013\end{array}$} \\
\hline & & $\downarrow$ & $\mathrm{rt}$ & \\
\hline \multirow{2}{*}{$\begin{array}{c}\text { Chen, } 1989 \\
\mathrm{FO}_{2} \mathrm{SCF}_{2} \mathrm{CO}_{2} \mathrm{Me}\end{array}$} & Cul, DMF, $60-80^{\circ} \mathrm{C}$ & \multirow{2}{*}[\mathrm{CuCF}_{3}]{} & $\mathrm{K}\left[\mathrm{Cu}\left(\mathrm{O}^{\prime} \mathrm{Bu}\right)_{2}\right], \mathrm{DMF}$ & \\
\hline & catalytic conditions & & $-40^{\circ} \mathrm{C}$ to $\mathrm{rt}$ & $\mathrm{CF}_{3}$ \\
\hline \multirow{2}{*}{$\begin{array}{c}\text { Burton and Chen, } \\
1989,1993-1994 \\
\mathrm{HalCF}_{2} \mathrm{CO}_{2} \mathrm{Me}\end{array}$} & Cul, KF & $\uparrow$ & $\mathrm{CuCl}, \mathrm{KO} \mathrm{B}^{\mathrm{B} u}, \mathrm{DMF}$ & \multirow{2}{*}{$\begin{array}{l}\mathrm{Hu}, 2015 \\
\mathrm{PhSOCF}_{3}\end{array}$} \\
\hline & $\mathrm{DMF}, 120^{\circ} \mathrm{C}$ & & rt & \\
\hline
\end{tabular}

Scheme 6 Examples of synthesis of [ $\left.\mathrm{CuCF}_{3}\right]$ using organic sources

An alternative to the direct decarboxylation of trifluoromethylated acetates is the use of a difluoromethylene moiety as a 'masked' $\mathrm{CF}_{3}{ }^{-}$synthon (Scheme 6). In this venue, it is worth mentioning the important contribution by Chen and coworkers who, back in 1989, uncovered a route to access trifluoromethyl copper(I) complexes by sequential decarboxylation and $\mathrm{SO}_{2}$ extrusion of methyl fluorosulphonyldifluoroacetate. ${ }^{10}$ This trifluoromethylating agent is activated at $60{ }^{\circ} \mathrm{C}$ and it is compatible with catalytic amounts of copper. Initially, the authors hypothesized the formation of difluorocarbene as intermediate but their attempts to trap it, using alkenes as acceptors, failed. Then, they proposed the formation of a heteroleptic cuprate, $\left[\mathrm{Cu}\left(\mathrm{CF}_{3}\right) \mathrm{I}\right]^{-}$, as the reactive species in the nucleophilic trifluoromethylation reaction (see Section 2). The same group reported in 2016 an alternative route to prepare $\left[\mathrm{CuCF}_{3}\right]$ through a decomposition/comproportionation sequence starting from $\mathrm{Cu}\left(\mathrm{FO}_{2} \mathrm{SCF}_{2} \mathrm{CO}_{2}\right)_{2}$ and elemental copper (Scheme 7). ${ }^{18}$ This new $\mathrm{CF}_{3}$ source is more efficient than the previous one for the trifluoromethylation of aryl and heteroaryl iodides. In order to gain mechanistic insights on the nature of the reactive species, the authors monitored the reaction of $\mathrm{Cu}\left(\mathrm{FO}_{2} \mathrm{SCF}_{2} \mathrm{CO}_{2}\right)_{2}$ and $\mathrm{Cu}$ in DMF by ${ }^{19} \mathrm{~F}$ NMR spectroscopy. Although at the beginning of the reaction only $\left[\mathrm{Cu}\left(\mathrm{CF}_{3}\right)_{2}\right]^{-}$was detected, over time (DMF)Cu( $\left(\mathrm{CF}_{3}\right)$ was also observed. The proposed mechanism for the generation of the active copper species is depicted in Scheme 7. Other less used $\mathrm{CF}_{3}$ sources for the in-situ generation of $\left[\mathrm{CuCF}_{3}\right]$ is $\mathrm{HalCF}_{2} \mathrm{CO}_{2} \mathrm{Me}$ in combination with an external fluoride source (Scheme 6). ${ }^{19}$

$\mathrm{Cu}\left(\mathrm{FO}_{2} \mathrm{CF}_{2} \mathrm{SCO}_{2}\right)_{2}+\mathrm{Cu} \underset{\mathrm{DMF}, \mathrm{rt}}{\stackrel{-\mathrm{CO}_{2,}-\mathrm{SO}_{2}}{\longrightarrow}} \mathrm{Cu}^{2+}+2: \mathrm{CF}_{2}+2 \mathrm{~F}^{-} \longrightarrow 2 \mathrm{Cu}^{+}+2 \mathrm{CF}_{3}-\equiv\left[\mathrm{CuCF}_{3}\right]$

Scheme 7 Mechanism of the trifluoromethylation using $\mathrm{Cu}\left(\mathrm{FO}_{2} \mathrm{SCO}_{2}\right)_{2}$ and $\mathrm{Cu}$ (See Ref. 18 for further details)

Another alternative to the decarboxylative route is the combination of trifluoromethyl ketones, sulfone ${ }^{20}$ or sulfoxide and a strong organic base such as tert-butoxides. In this context, Mikami et al. studied the mechanism of the generation of the trifluoromethyl copper(I) complexes starting from a pre-formed $\mathrm{K}\left[\mathrm{Cu}\left(\mathrm{O}^{t} \mathrm{Bu}\right)_{2}\right]$ and trifluoromethyl aryl ketones. ${ }^{21}$ Strikingly, tetrahedral intermediates (Scheme 8a) were detected at $-30{ }^{\circ} \mathrm{C}$ by ${ }^{19} \mathrm{~F}$ NMR spectroscopy and the evolution of the reaction towards $\left[\mathrm{CuCF}_{3}\right]$ was described when warming up the reaction mixture. 
Regarding trifluoromethylsulfoxides as $\mathrm{CF}_{3}$ source, in 2015, $\mathrm{Hu}$ and co-workers developed a methodology for the trifluoromethylation of aryl halides, activated aryl bromides, terminal alkynes and aryl boronic acids. ${ }^{22}$ The reaction mixture of $\mathrm{CuCl}, \mathrm{KO}^{t} \mathrm{Bu}$ and $\mathrm{PhSOCF}_{3}$ in $\mathrm{DMF}$ gave rise to a $99 \%$ yield of $\left[\mathrm{CuCF}_{3}\right]$ as a mixture of (DMF)CuCF $3(89 \%)$ and $\left[\mathrm{Cu}\left(\mathrm{CF}_{3}\right)_{2}\right]^{-}$ $(10 \%)$. As it was previously described by Grushin, the addition of $\mathrm{Et}_{3} \mathrm{~N} \cdot 3 \mathrm{HF}$ could stabilize the $\left[\mathrm{CuCF}_{3}\right]$ species increasing the amount of the cuprate salt (the proportion in this case is not mentioned).

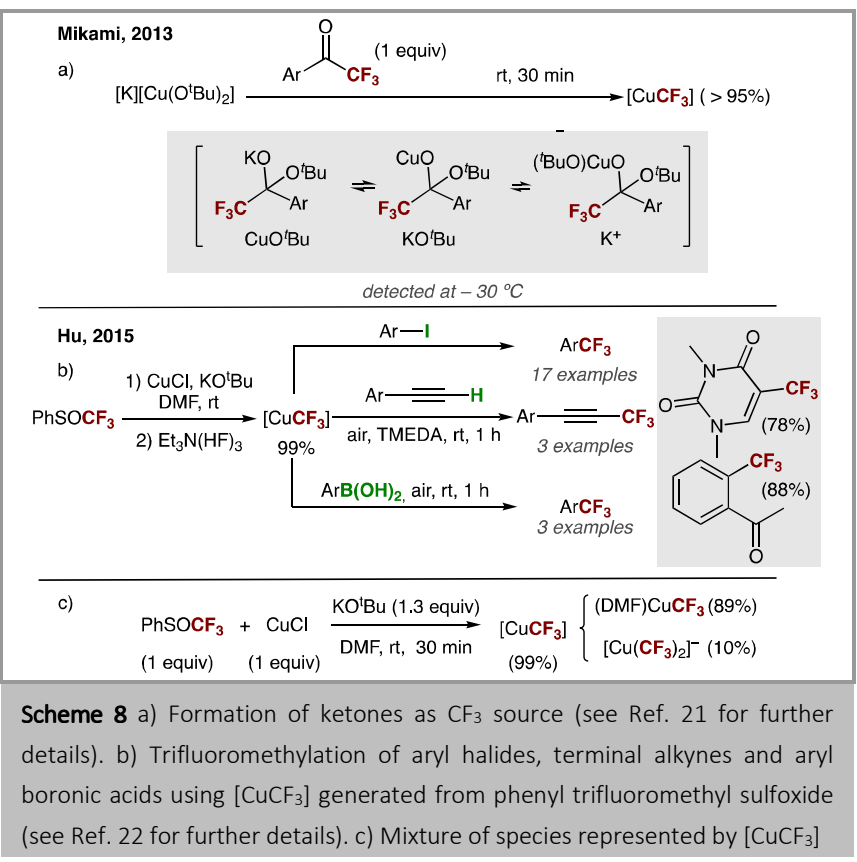

\subsection{Transmetalation}

In this section, we have considered the $\mathrm{CF}_{3}$ exchange from a trifluoromethyl organometallic species to copper. We have divided them in three categories: (i) transition metals; ${ }^{23}$ (ii) silanes and stannanes and finally (iii) boron-containing species.

\subsubsection{Transition metals}

The first example of the formation of $\left[\mathrm{CuCF}_{3}\right]$ by a group transfer from a trifluoromethyl metal complex to copper was reported by Yagupolskii and co-workers using $\mathrm{Hg}\left(\mathrm{CF}_{3}\right)_{2}$ or $\mathrm{Hg}\left(\mathrm{CF}_{3}\right) \mathrm{I} .{ }^{24}$ This early report was applied in the activation of aliphatic, aromatic and heterocycles molecules. In 1985, Burton et al prepared different trifluoromethylated zinc and cadmium complexes such as $\mathrm{M}\left(\mathrm{CF}_{3}\right)_{\mathrm{n}} \mathrm{X}_{2-\mathrm{n}}$ that could transfer its $\mathrm{CF}_{3}$ moiety to copper. ${ }^{25}$ This mixture of $\left[\mathrm{CuCF}_{3}\right]$ species was able to activate iodobenzene forming trifluorotoluene in $80 \%$ yield. In 1989, Burton et al. proposed the presence of $(\mathrm{CdI})\left[\mathrm{Cu}\left(\mathrm{CF}_{3}\right)_{2}\right]$ and $(\mathrm{Cd})\left[\mathrm{Cu}\left(\mathrm{CF}_{3}\right) \mathrm{I}\right]$ in the reaction mixture. ${ }^{7 a}$ In general, the $\mathrm{CF}_{3}$ transfer to copper(I) salts from Cd-complexes is faster than from $\mathrm{Zn}$-complexes. ${ }^{26}$ However, due to practical reasons, zinc has been more exploited as starting material in this type of methodologies (Scheme 9).

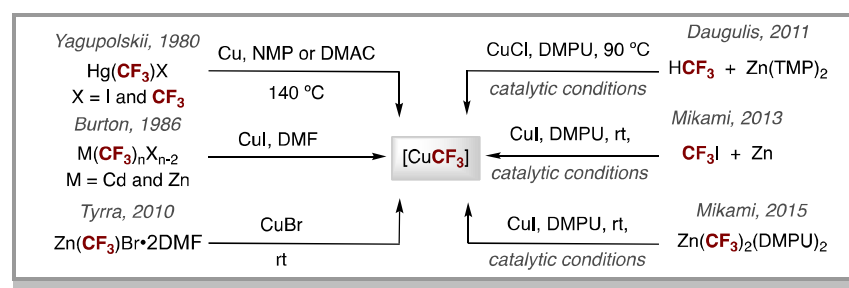

Scheme 9 Examples of synthesis of $\left[\mathrm{CuCF}_{3}\right]$ using different transition metals

In 2011, Daugulis et al. introduced an interesting approach to this field: the arylation of readily available $1 \mathrm{H}$-perfluoroalkanes by its deprotonation with a metal base such as $\mathrm{TMP}_{2} \mathrm{Zn}$ (TMP = bis2,2,6,6-tetramethylpiperidide) using catalytic amounts of copper and phenanthroline as ligand (Scheme 10a).27 In the transmetalation reaction from $\mathrm{Zn}$ to $\mathrm{Cu}$, a mixture of pentafluoroethyl copper complexes including heteroleptic and homoleptic cuprates was again observed by ${ }^{19} \mathrm{~F}$ NMR. The proposed reaction mechanism involved an initial deprotonation of the perfluoroalkane by the zinc amide base. After that, the transmetalation to $\mathrm{CuCl}$ takes place. Interestingly, they proposed that this event could be the turnover-limiting step when using certain perfluoroalkyl sources. Thus, once this reaction happens, the cuprates can react with the aryl iodide directly or through neutral species (Scheme 10b). The scope was quite limited in terms of trifluoromethylated products obtaining only one example in moderate yield (51\%). However, products decorated with perfluoroalkylated chains were generated in good yields.

Scheme 10 a) Perfluoroalkylation of aryl halides (See Ref. 27 for further
details). b) Proposed reaction mechanism

Later, in 2013, Mikami described the trifluoromethylation of aryl and heteroaryl iodides catalyzed by copper(I) salt and phenanthroline using $\mathrm{Zn}\left(\mathrm{CF}_{3}\right) \mathrm{I}$, prepared in-situ from trifluoromethyl iodide and $\mathrm{Zn}$ dust in DMPU (1,3-dimethyl3,4,5,6-tetrahydro-2-(1H)pyrimidone). ${ }^{28}$ The methodology was not successful when using electron-donating substituents in the aryl iodides (scheme 11a). In order to gain insight into each step of the Cu-catalyzed $\mathrm{Zn}$-mediated trifluoromethylation, they performed a ${ }^{19} \mathrm{~F}$ NMR spectroscopic analysis, observing a Schlenk equilibrium of $\mathrm{Zn}\left(\mathrm{CF}_{3}\right) \mathrm{I}$ with $\mathrm{Zn}\left(\mathrm{CF}_{3}\right)_{2}$ and $\mathrm{ZnI}_{2}$. The addition of $\mathrm{CuI}$ to this solution resulted in the transmetalation of the $\mathrm{CF}_{3}$ group from zinc to copper observing two singlet peaks of the cuprate species, $\left[\mathrm{Cu}\left(\mathrm{CF}_{3}\right) \mathrm{I}\right]^{-}$and $\left[\mathrm{Cu}\left(\mathrm{CF}_{3}\right)_{2}\right]^{-}$(scheme $\left.11 \mathrm{~b}\right)$. In this case, the neutral (DMPU) $\mathrm{CuCF}_{3}$ species $(\delta \approx-26 \mathrm{ppm}$ ), was not observed. The addition of aryl iodide to this mixture led to the formation of the trifluoromethyl organic molecule with the consumption of the cuprates $\left[\mathrm{Cu}\left(\mathrm{CF}_{3}\right) \mathrm{I}\right]^{-}$and $\left[\mathrm{Cu}\left(\mathrm{CF}_{3}\right)_{2}\right]^{-}$. The non-efficient and complex transmetalation reaction complicates the mechanistic picture and the real potential of both cuprate species in the trifluoromethylation of aryl halides was not clearly disclosed. In 2015, the same group provided a mechanistic 
proposal for the trifluoromethylation of aryl and heteroaryl iodides using isolated $\mathrm{Zn}\left(\mathrm{CF}_{3}\right)_{2}(\mathrm{DMPU})_{2}$, involving a $\mathrm{Cu}^{\mathrm{I} / \mathrm{III}}$ catalytic cycle (scheme 11c). ${ }^{29}$ Again, the impossibility to access selectively the copper species prevented the study of their real role in the trifluoromethylation reaction.

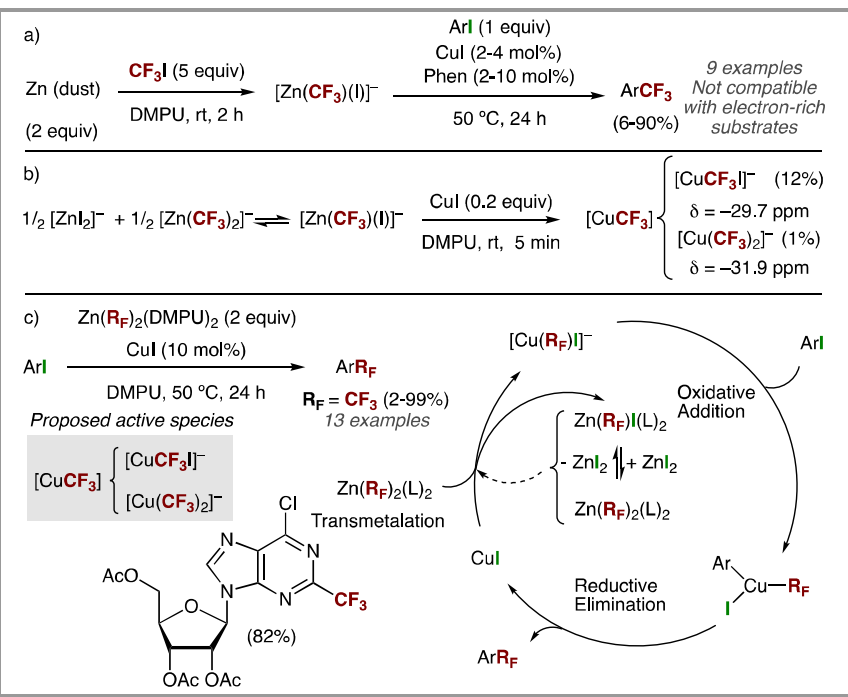

Scheme 11 a) Cu-catalyzed Zn-mediated trifluoromethylation of aryl halides (See Ref. 28 for further details). b) Species in the transmetalation reaction. c) Cu-catalyzed Zn-mediated trifluoromethylation of aryl halides using isolable $\mathrm{Zn}$ reagents (See Ref. 29 for further details). d) Proposed reaction mechanism

\subsection{2 $\quad \mathrm{R}_{3} \mathrm{MCF}_{3}(\mathrm{M}=\mathrm{Si}, \mathrm{Sn})$}

Among the different nucleophilic trifluoromethylating sources, trifluoromethyltrimethylsilane $\left(\mathrm{Me}_{3} \mathrm{SiCF}_{3}\right)$ trifluoromethyltriethylsilane $\left(\mathrm{Et}_{3} \mathrm{SiCF}_{3}\right) \quad$ and tributyl(trifluoromethyl)stannane $\quad\left(\mathrm{Bu}_{3} \mathrm{SnCF}_{3}\right) \quad$ have demonstrated their efficiency in combination with activators such as fluorides or tert-butoxide salts. It is noteworthy to mention that the most widely used Ruppert-Prakash reagent $\left(\mathrm{Me}_{3} \mathrm{SiCF}_{3}\right)$ is utilized not only for the in-situ formation of "ligandless" [ $\left.\mathrm{CuCF}_{3}\right]$ species but also to synthesize well-defined trifluoromethyl copper(I) complexes (see Section 4).

In 1991, Fuchikami et al. applied for the first time the introduction of a $\mathrm{CF}_{3}$ group onto organic halides using $\mathrm{CuI}$, $\mathrm{Et}_{3} \mathrm{SiCF}_{3}$ and $\mathrm{KF} .{ }^{30}$ In 2009, the same reaction was reported in a catalytic version using diamine ligands to favor the solubility of the $\mathrm{CuI}$ and accelerate the transference of the $\mathrm{CF}_{3}$ moiety before its decomposition. ${ }^{31}$ This elegant approach led to different trifluoromethylation protocols using copper as catalyst and silanes as the $\mathrm{CF}_{3}$ source. ${ }^{32}$

Later, in 2012, $\mathrm{Hu}$ and co-workers reported the use of $\mathrm{Me}_{3} \mathrm{SiCF}_{3}$ in the preparation of $\left[\mathrm{CuCF}_{3}\right]$ for the trifluoromethylation of a wide variety of $\alpha$-diazo esters containing aryl, benzyl, or other alkyl substituent in moderate to excellent yield. (See Scheme 12a). ${ }^{33}$ To gain more insights into the reaction mechanism, they tentatively described the composition of $\left[\mathrm{CuCF}_{3}\right]$ species by ${ }^{19} \mathrm{~F}$ NMR spectroscopy. Their proposal involves the activation of $\left[\mathrm{Cu}\left(\mathrm{CF}_{3}\right) \mathrm{I}\right]^{-}$by water, which scavenges the $\mathrm{I}^{-}$forming a hydrated iodide ion, affording $\mathrm{CuCF}_{3}$.diazoester, the proposed active species (See Scheme 12b). Their hypothesis was supported by the decrease on the reaction efficiency when less amount of water ( $<10$ equiv) is used or external $\mathrm{KI}$ is added. Remarkably, they also described that the amount of $\left[\mathrm{CuI}_{2}\right]^{-}$can affect the chemical shift of $\left[\mathrm{Cu}\left(\mathrm{CF}_{3}\right) \mathrm{I}\right]^{-}$species. Thus, they suggested that a more appropriate way to denominate these species would be $\left\{\left[\mathrm{Cu}\left(\mathrm{CF}_{3}\right) \mathrm{I}\right]_{\mathrm{x}}\right\}^{\mathrm{x}}-\left\{\left[\mathrm{CuI}_{2}\right]_{\mathrm{y}}\right\}^{\mathrm{y}}$.

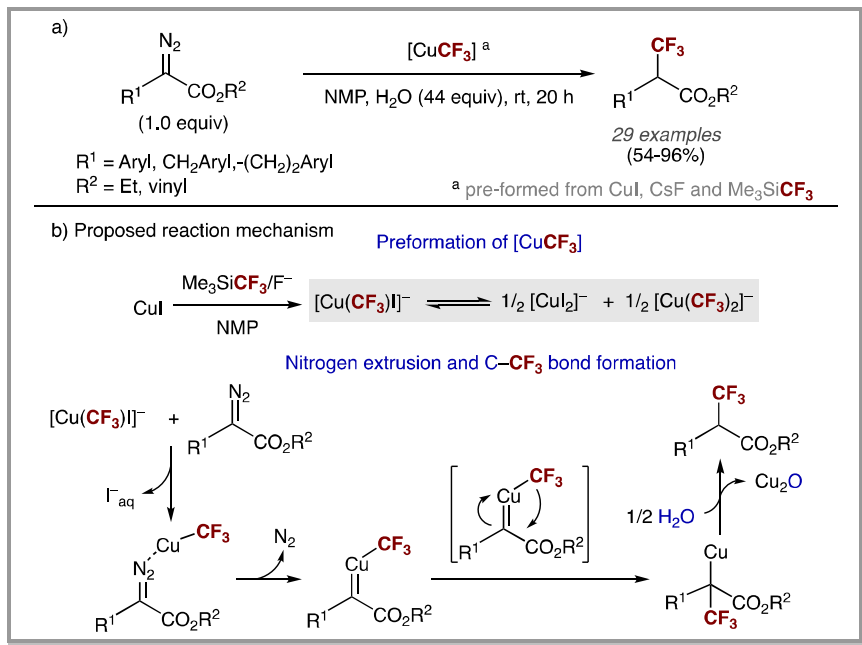

Scheme 12 a) Scope and reaction conditions for the nucleophilic trifluoromethylation of $\alpha$-diazoesters (See Ref. 33 for further details). b) Proposed mechanism for nitrogen extrusion and $\mathrm{C}-\mathrm{C}$ bond formation

The broad applicability of $\mathrm{Me}_{3} \mathrm{SiCF}_{3}$ has allowed a shift in the paradigm of traditional trifluoromethylation methodologies based on cross-coupling concepts towards oxidative trifluoromethylation reactions. This concept allows the connection of nucleophilic $\mathrm{CF}_{3}$ with other nucleophiles under oxidative conditions. ${ }^{34}$ In 2010, Qing et al. reported the first example of the coupling of the Ruppert-Prakash reagent and boronic acids or alkynes in the presence of [Cu(OTf)] $\cdot \mathrm{C}_{6} \mathrm{H}_{6}$ or $\mathrm{CuI} /$ phen, respectively (Scheme 13). ${ }^{35}$ In 2012, the same research group reported the catalytic version of the aerobic oxidative trifluoromethylation of terminal alkynes. ${ }^{36}$

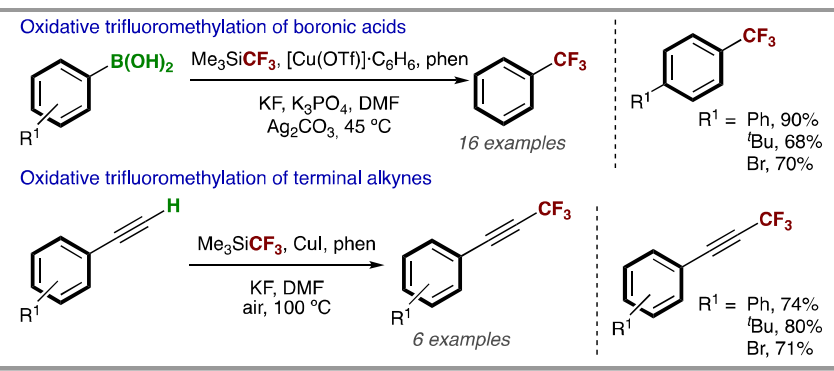

Scheme 13 General schematic for the oxidative trifluoromethylation of boronic acids and terminal alkynes (See Ref. 34-35 for further details)

Interestingly, the authors pointed out the necessity of a slow addition of $\mathrm{Me}_{3} \mathrm{SiCF}_{3}$ to the reaction mixture in order to avoid the decomposition of the silane before the $\mathrm{CF}_{3}$ fragment is transferred to the copper center. This step was limited by the slow recovering of the copper catalyst. In this regard, in 2013, Maseras and Jover proposed, based on DFT calculations, the reductive elimination as the rate-determining step of the oxidative trifluoromethylation, supporting the challenges associated to the catalyst recovering (Scheme 14). ${ }^{37}$

Further mechanistic investigations using electrospray-ionization mass spectrometry (ESI-MS) by Koszinowski et al. aimed to shed 
light into the nature of the intermediates involved in these transformations. ${ }^{38}$ In the absence of the alkyne component, the homoleptic ate-type complexes $\left[\mathrm{Cu}\left(\mathrm{CF}_{3}\right)_{2}\right]^{-}$and $\left[\mathrm{Cu}\left(\mathrm{CF}_{3}\right)_{4}\right]^{-}$were detected from the mixture of $\mathrm{CuI}, \mathrm{KF}$ and $\mathrm{Me}_{3} \mathrm{SiCF}_{3}$ in different solvents such as acetonitrile, tetrahydrofurane or $\mathrm{N}, \mathrm{N}$-dimethylformamide. Remarkably, when using the alkynes, the authors detected copper(III) species such as $\left[\mathrm{Cu}\left(\mathrm{CF}_{3}\right)_{3} \mathrm{R}\right]^{-}$, presumably the intermediate involved in the reductive elimination step. In the presence of $N, N$-bidentate-ligands, the authors were able to discard the intermediacy of $\left[(N, N) C u\left(C_{3}\right) R\right]^{-}$in the oxidative process based on the unfruitful attempts to detect them even when modifying the ancillary ligand. Despite this remarkable mechanistic hint, a neutral $N, N$-bidentate-ligand-based mechanism, such as the one proposed by Maseras, could be simultaneously taking place and being overlooked using ESI MS techniques.

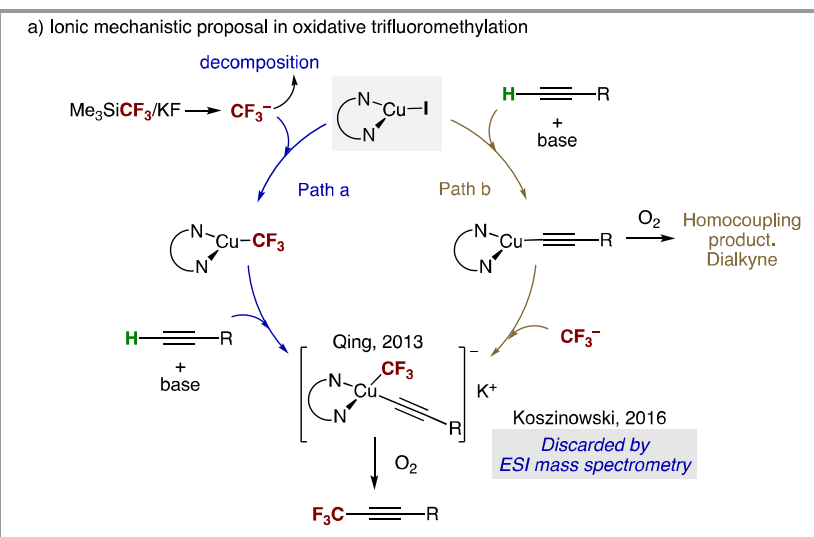

b) Neutral mechanistic proposal in oxidative trifluoromethylation ${ }^{\mathrm{a}}$

Maseras, 2013

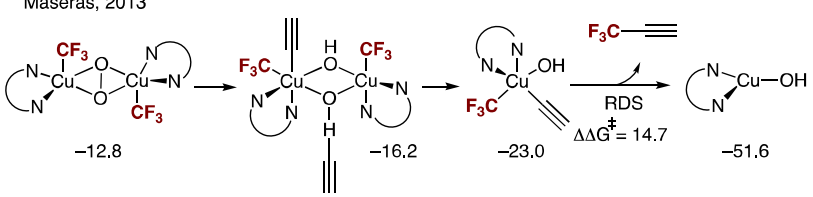

${ }^{a}$ Energies in kcal/mol. Origin, not shown, in (NNN)Cul + reagents)

Scheme 14 a) Mechanistic proposals for the oxidative coupling of terminal alkynes and the trifluoromethyl moiety. b) Key intermediates proposed by Maseras based on DFT calculations

Regarding the employment of stannanes, in 2012, Shoenebeck et al. presented a new methodology combining $\mathrm{Bu}_{3} \mathrm{SnCF}_{3}$, as $\mathrm{CF}_{3}$ source, and $\mathrm{CuI} / \mathrm{KF}$ for the nucleophilic trifluoromethylation of aryl iodides (Scheme 15). ${ }^{39}$ The authors explained that the trifluoromethylation reaction is performed by $\mathrm{CuCF}_{3} \cdot \mathrm{KBr}$ and $\left[\mathrm{Cu}\left(\mathrm{CF}_{3}\right)_{2}\right]^{-}$based on ${ }^{19} \mathrm{~F}$ NMR spectroscopy. In addition, radical mechanisms were discarded based on the lack of rearranged product when using radical clock substrates. In this interesting piece of work, although the complete mechanistic scenario for the formation of the $\mathrm{C}-\mathrm{C}$ was not deeply discussed, a comparison between $\mathrm{Me}_{3} \mathrm{SiCF}_{3}$ and $\mathrm{Bu}_{3} \mathrm{SnCF}_{3}$ as transmetalating agents is presented. The transmetalation is faster in the case of the Ruppert-Prakash reagent but the overall performance in the trifluoromethylation of aryl iodides is quite similar. Regarding the scope, there is no a big difference between the use of the silane or stannane. However, the trifluoromethyl silanes has been by far more studied than the stannane and, therefore, more information can be found in the literature.

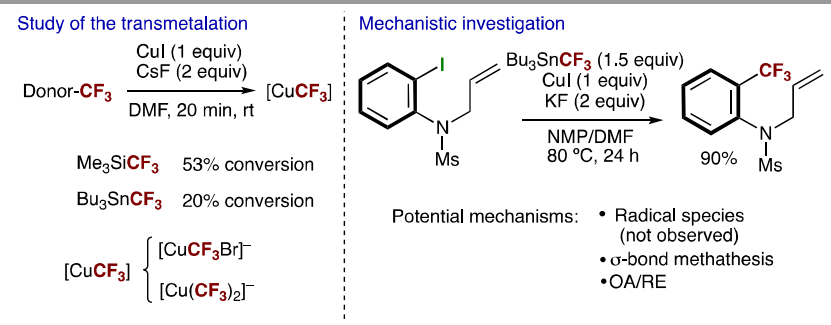

Scheme 15 Comparative study between $\mathrm{Me}_{3} \mathrm{SiCF}_{3}$ and $\mathrm{Bu}_{3} \mathrm{SnCF}_{3}$ in the transmetalation reaction and mechanistic proposals (see Ref. 39 for further details)

\subsubsection{Borates and borazines}

In 2011, Goossen et al. disclosed the capability of potassium (trifluoromethyl)trialkoxyborates as nucleophilic $\mathrm{CF}_{3}$ sources in Cu-catalyzed trifluoromethylation reactions (Scheme 14a).11,40 During their stoichiometric experiments they detected the formation of the heteroleptic cuprate $\left[\mathrm{Cu}\left(\mathrm{CF}_{3}\right) \mathrm{I}\right]^{-}$when mixing the potassium (trifluoromethyl)trimethoxyborate and equimolar amounts of CuI in DMF at room temperature (Scheme 14b). The catalyzed version was achieved by using 1,10-phenantroline as ligand, that it is proposed to increase the nucleophilicity of the metal center. This is subsequently translated into an acceleration of the $\sigma$-bond metathesis step and, therefore, in a fast recovering of the copper catalyst (Scheme 14c). The scope of this reaction allowed the incorporation of trifluoromethyl group in good yields in aryl iodides bearing electron-rich and -poor substituents.

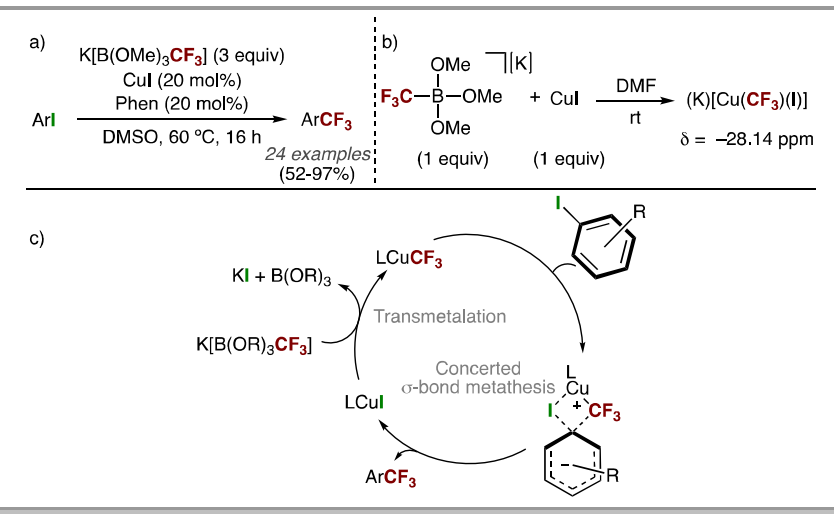

Scheme 16 a) Cu-catalyzed trifluoromethylation of aryl halides using potassium (trifluoromethyl)trialkylborates as $\mathrm{CF}_{3}$ source (See Ref. 40 for further details). b) Transmetalation reaction. c) Proposed reaction mechanism

In 2018, Szymczak and co-workers presented an interesting strategy for the introduction of a $\mathrm{CF}_{3}$ group into different inorganic electrophiles using a fluoroform-derived borazine (Scheme 17). ${ }^{41}$ In particular, the reaction of $\mathrm{CuI}$ and borazine- $\mathrm{CF}_{3}$ in DMSO gives rise a mixture of (DMSO) $\mathrm{CuCF}_{3}(19 \%)$ and $\left[\mathrm{Cu}\left(\mathrm{CF}_{3}\right) \mathrm{I}\right]^{-}(63 \%)$ that reacts with 4-iodobiphenyl at $80^{\circ} \mathrm{C}$ during 12 hours forming the trifluoromethyl organic molecule in $66 \%$ yield.

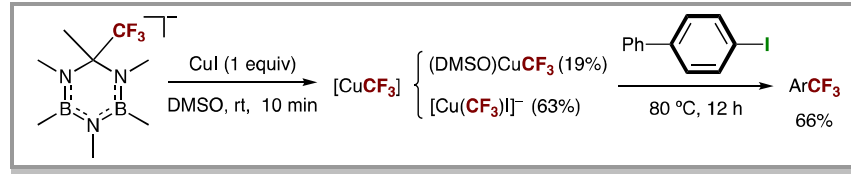

Scheme 17 a) Transmetalation reaction from borazine to copper and the trifluoromethylation reaction of 4-iodobiphenyl (See Ref. 41 for further details) 


\section{Well-defined active trifluoromethyl copper(I) species}

Over the past decade, different literature precedents have demonstrated the exceptional activity of well-defined $\mathrm{LCu}\left(\mathrm{CF}_{3}\right)$ complexes, supported by ancillary ligands, in stoichiometric nucleophilic trifluoromethylation reactions. Most of these neutral copper(I) complexes are in equilibrium in polar solvents with salts containing the bis-trifluoromethyl cuprate as anion. This is remarkable because the majority of these trifluoromethylation reactions, as it will be shown, are performed in DMF that shifts the equilibrium towards the ionic part.

We have organized this section based on the nature of the ancillary ligand: (i) NHC-carbenes; (ii) bidentate nitrogen ligands and (iii) phosphines. We discuss their synthesis, substrate scope in the trifluoromethylation reactions and relevant mechanistic features.

\subsection{NHC-carbene copper (I) complexes}

In 2008, Vicic et al. disclosed, for the first time, the synthesis of a well-defined trifluoromethyl copper(I) complexes using carbenes (SIiPr or IPr) as ancillary ligands. ${ }^{4 \mathrm{~b}}$ These stabilized copper complexes were synthetized by the treatment of tertbutoxide copper derivatives with $\mathrm{Me}_{3} \mathrm{SiCF}_{3}$, affording (SIiPr) Cu(CF $\mathrm{CF}_{3}$ in $91 \%$ yield and mixture of copper complexes for $\mathrm{L}=\operatorname{IPr}$ (Scheme 18a). The authors tested their ability as trifluoromethylating agents, observing a higher activity when using the copper compound stabilized with the saturated ligand (SIiPr). They observed a dramatic solvent effect, being DMF crucial to enhance the reactivity of the trifluoromethylation reactions. Till that date, the employment of $(\mathrm{SIiPr}) \mathrm{CuCF}_{3}$ or its insitu generation showed the best performance in trifluoromethylation protocols. However, the formation of trifluoromethylated products decorated with electron donating groups is limited when using this procedure. The same year, the scope of this methodology was extended to electron-rich aryl halides by the use of (SIMes) $\mathrm{CuCF}_{3}$ (AsImes). ${ }^{4 c}$ Interestingly, in $\mathrm{THF}$, this neutral complex is in equilibrium with an ionic part, [(SIMes) $\left.)_{2} \mathrm{Cu}\right]\left[\mathrm{Cu}\left(\mathrm{CF}_{3}\right)_{2}\right]$ (Bsimes) that was characterized, for the first time, by X-ray diffraction (Scheme 18b). The mixture of Asimes and Bsimes, in neat aryl halide or using the solvent mixture benzene:DMI, exhibited a superior activity than the previously described employing (SIiPr) $\mathrm{CuCF}_{3}$ (they compare neat reaction conditions vs DMF). Kinetic studies suggested that (SIMes) $\mathrm{CuCF}_{3}$ (Asımes) exhibited a higher activity as trifluoromethylating reagent. However, since Asimes and Bsimes are presented in the reaction media is challenging to univocally stablish the origin of this outstanding performance.

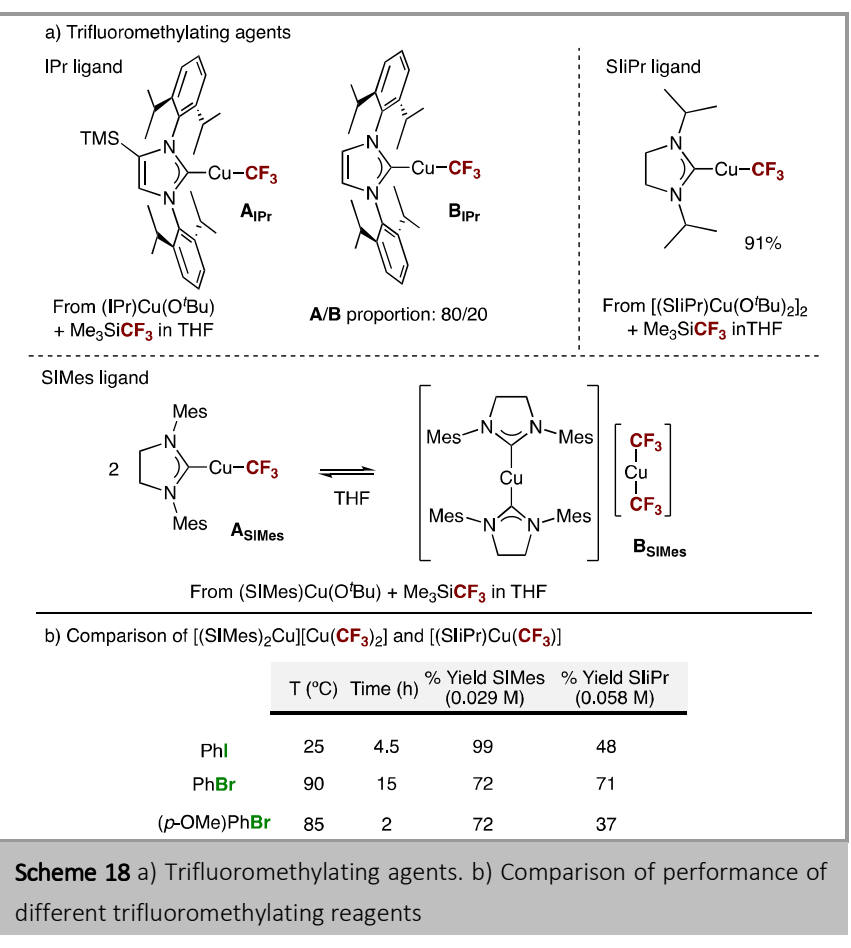

\section{$4.2 \quad\left(N^{\wedge} N\right)$ copper $(I)$ complexes}

In 2011, Hartwig et al. described the synthesis of (phen) $\mathrm{Cu}\left(\mathrm{CF}_{3}\right)$ by the reaction of $\left[\mathrm{CuO}^{t} \mathrm{Bu}\right]_{4}$ with 1,10-phenantroline, followed by the addition of $\mathrm{Me}_{3} \mathrm{SiCF}_{3}{ }^{4 \mathrm{~d}}$ Although this species was previously proposed to be catalytically active in a seminal work of Amii et al., in that work there was not any experimental evidence of its formation. ${ }^{31}$ As described for [(SIMes)Cu( $\left.\left.\mathrm{CF}_{3}\right)\right]$, (phen) $\mathrm{Cu}\left(\mathrm{CF}_{3}\right)$ ( $\left.\mathbf{A}_{\text {phen }}\right)$ is in equilibrium with an ionic part, $\left[(\text { phen })_{2} \mathrm{Cu}\right]\left[\mathrm{Cu}\left(\mathrm{CF}_{3}\right)_{2}\right]$ (B $\left.\mathbf{B}_{\text {phen }}\right)$, in different solvents such as dichloromethane, tetrahydrofurane and $\mathrm{N}, \mathrm{N}$ dimethylformamide. Conductivity and spectroscopic techniques were used to confirm the stoichiometric of the salt.

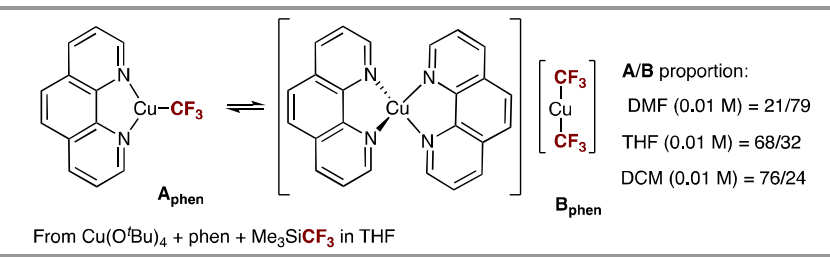

Scheme 19 Equilibrium between (phen) $\mathrm{CuCF}_{3}$ and $\left[(\text { phen })_{2} \mathrm{Cu}\right]\left[\mathrm{Cu}\left(\mathrm{CF}_{3}\right)_{2}\right]$ in different solvents

The described protocol for the trifluoromethylation of aryl iodides afforded high yields of the desired products even when using electron-donating substituents. On the other hand, the trifluoromethylation of aryl bromides was shown to be challenging even using higher temperatures and electron-poor substrates. Regarding the mechanism, the use of radical clock experiments supported the absence of radicals during the transformation. The same research group has also reported the functionalization of heteroaryl bromides ${ }^{4 k}$ and the oxidative trifluoromethylation of arylboronate esters ${ }^{4 \mathrm{~g}}$ and aryl silanes ${ }^{4 \mathrm{~m}}$ (Scheme 20). The arylboronate esters are generated by the reaction of arenes or aryl bromides with $\mathrm{B}_{2} \mathrm{pin}_{2}$ using iridium or palladium catalysts, respectively. Then, the trifluoromethyl group replaces the boronate moiety in the aryl moiety under 
oxidative Chan-Lam-type conditions. ${ }^{42}$ This new one-pot methodology permitted not only the regioselective functionalization of arenes but also the expansion of the scope to aryl bromides. Regarding the aryl silanes, this new oxidative protocol was extended to pharmaceutically active molecules, inaccessible through other synthetic routes and using easily accessible starting materials. It is worth mentioning that all the aforementioned described reactions were performed in DMF where there is a mixture $\mathbf{A}_{\text {phen }}$ : $\mathbf{B}_{\text {phen }}(0.01 \mathrm{M}, 21: 79$ respectively). Therefore, the participation of both complexes as trifluoromethylating reagents could not be completely ruled out. Remarkably, the broad applicability of (phen) $\mathrm{CuCF}_{3}$ resulted in its commercialization, as Trifluoromethylator ${ }^{\mathrm{TM}} .{ }^{43}$

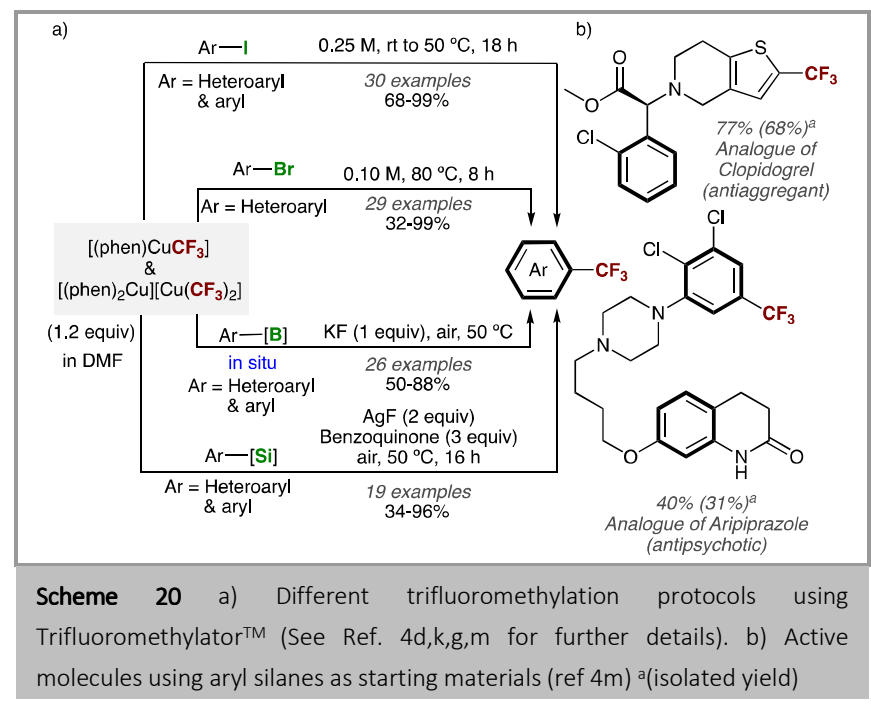

\subsection{Phosphine stabilized copper(I) complexes}

In 2011, Grushin et al. reported an exhaustive study on the

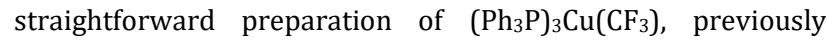
described by Komiya et al. ${ }^{44}$ and (phen) $\mathrm{Cu}\left(\mathrm{PPh}_{3}\right)\left(\mathrm{CF}_{3}\right)$, analogous to Hartwig's trifluoromethylator (see Scheme 21a).4e The later one is in equilibrium at room temperature with [(phen $\left.)_{2} \mathrm{Cu}\right]\left[\mathrm{Cu}\left(\mathrm{CF}_{3}\right)_{2}\right]$ and $\mathrm{PPh}_{3}$ in $\mathrm{CD}_{2} \mathrm{Cl}_{2}$, analogous to the examples described by Vicic and Hartwig. ${ }^{4 b-c}$ Both complexes were exceptionally good as trifluoromethylating agents of aryl and heteroaryl iodides. In the case of $\left(\mathrm{Ph}_{3} \mathrm{P}\right)_{3} \mathrm{Cu}\left(\mathrm{CF}_{3}\right)$, the addition of additives such as phen, Bpy or ${ }^{t} \mathrm{Bu}$-bpy favored the reaction, hampering the formation of side products like $\mathrm{HCF}_{3}$ and $\mathrm{PhCF}_{2} \mathrm{CF}_{3}$.

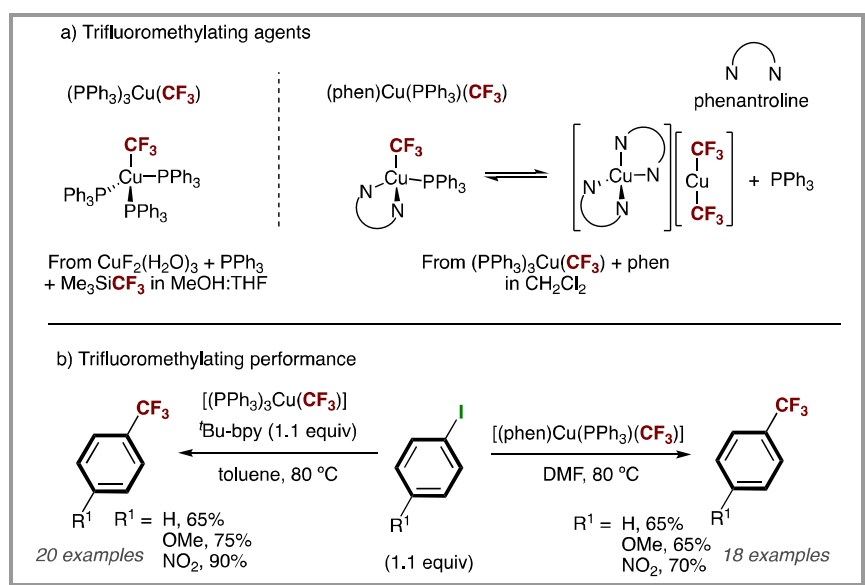

Scheme 21 a) Phosphine trifluoromethyl copper(I) complexes (See Ref. 4e for further details). b) Trifluoromethylation reaction using $\left(\mathrm{Ph}_{3} \mathrm{P}\right)_{3} \mathrm{Cu}\left(\mathrm{CF}_{3}\right)$ and (phen) $\mathrm{Cu}\left(\mathrm{PPh}_{3}\right)\left(\mathrm{CF}_{3}\right)$

\section{5}

\section{Recent advances on the reactivity of different trifluoromethylation protocols}

In 2017, Vicic et al. published an interesting work that compares the performance of previously described copper systems (Scheme 22).45 In this report, the authors used as $\mathrm{CF}_{3}$ sources not only well-defined trifluoromethyl copper reagents but also insitu generated $\left[\mathrm{CuCF}_{3}\right]$ by mixing $\mathrm{CuI} / \mathrm{TMSCF}_{3} / \mathrm{KF}^{4}{ }^{4-\mathrm{e}, 30}$ To that date, the described reaction conditions for the nucleophilic trifluoromethylation protocols were remarkably different hindering their comparison. In order to establish the relative reactivity between the copper systems, the authors selected as standard reaction conditions those described by Hartwig et al, using 4-iodo-1,1'-biphenyl as model system and DMF as solvent. After 24 hours at $50{ }^{\circ} \mathrm{C}$, the in-situ generated (phen) $\mathrm{Cu}\left(\mathrm{CF}_{3}\right)$ exhibited the best performance as trifluoromethylating agent.

Moreover, the authors also performed the nucleophilic trifluoromethylation of 4-iodo-1,1'-biphenyl using the reported conditions for each protocol. This implies the employment of different solvents, temperature and concentrations. Under these different reaction conditions, the in-situ generated (SIMes) $\mathrm{Cu}\left(\mathrm{CF}_{3}\right)$ showed the best performance, pointing out the crucial role of the solvent (benzene:DMI vs DMF). In general, the in-situ formation of the complexes gave a better outcome than the corresponding isolated ones. Interestingly, when using the isolated or the in-situ generated (SIMes) $\mathrm{Cu}_{\left(\mathrm{CF}_{3}\right)}$ for the functionalization of electron-rich substrates, the authors observed induction periods in the kinetic profiles of the product formation, suggesting a non-trivial behavior of these copper systems in solution. Based on their results, in this work, the authors encouraged the benchmarking in trifluoromethylation reactions to allow a fair comparison between new methods and the previously described ones under the same reaction conditions. 


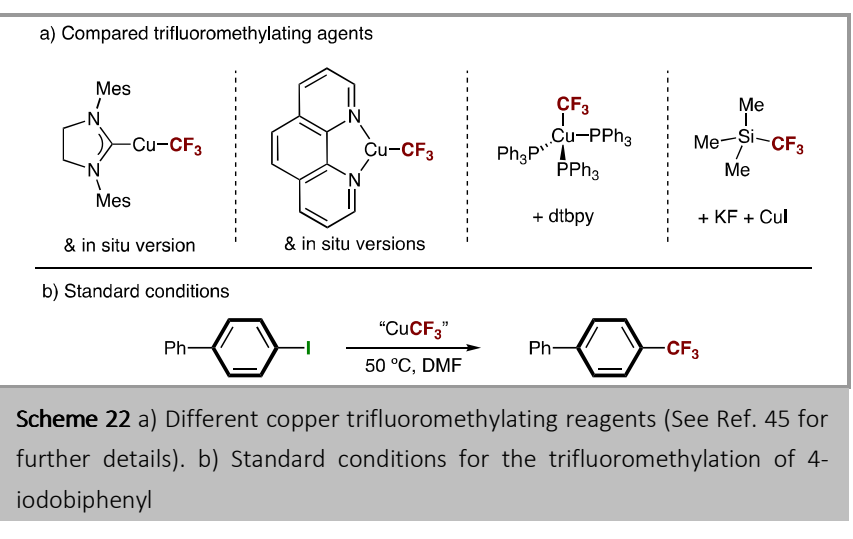

Despite the tremendous efforts on providing a comprehensive mechanistic picture on Cu-mediated trifluoromethylation reactions, there are still open questions that need to be addressed. This strongly encouraged our group to devote our efforts towards unveiling the real role of cuprate species in nucleophilic trifluoromethylation reactions. ${ }^{5}$ Recently, we were able to access, for the first time in a selective manner, $\left[\mathrm{Cu}\left(\mathrm{CF}_{3}\right)\right]_{2}$, ubiquitous in all the aforementioned transformations. We carried out the quantitative in-situ generation of these species through a transmetalation reaction using its analogous silver ate-type complex, $(\mathrm{Cs})\left[\mathrm{Ag}\left(\mathrm{CF}_{3}\right)\right]_{2}$ and $\mathrm{CuI}$. Under the standard conditions reported by Vicic, our salt outperformed the previously described nucleophilic copper systems. A combined experimental and computational studied uncovered a complex mechanistic picture through a $\mathrm{Cu}^{\mathrm{I} / \mathrm{III}}$ process with the participation of more reactive species such as (DMF) $\mathrm{CuCF}_{3}$, generated through multiple equilibria. These results not only give some hints about the behavior of different copper species in trifluoromethylation reactions but also suggest that the ate-type complexes actually act as a $\mathrm{CF}_{3}$ reservoir along these transformations. However, we believe that this should not be underestimated since these cuprates can generate more active species even when the neutral well-defined complexes are used as trifluoromethylating agent.

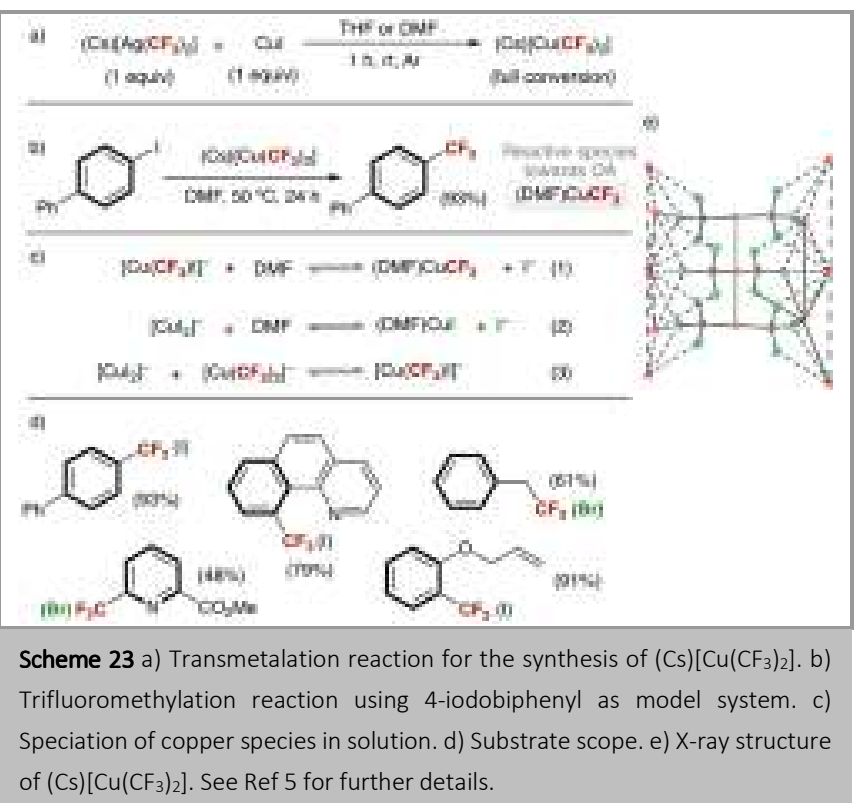

6

\section{Conclusions}

Over the past decades, trifluoromethyl copper(I) species have demonstrated their extraordinary activity as $\mathrm{CF}_{3}$ sources in nucleophilic trifluoromethylation reactions. These strategies allow the access to a wide variety of trifluoromethylated organic scaffolds, relevant in agrochemicals, pharmaceuticals or materials. Currently, there are two different approaches to access the active copper species in these transformations: their in-situ generation in the reaction media or the employment of welldefined and isolable ones, stabilized by ancillary ligands. In both cases, the investigation of the underlying reactions mechanisms has been hampered by the complex mixture of copper species observed in solution, involving neutral and/or ionic ones. In this context, tremendous efforts have been made by the organometallic community, merging experimental and computational strategies, in order to elucidate the nature of the reactive species, the dramatic effect of polar solvents in the success of the reactions and the real role of cuprate species in these transformations. Despite the major advances described in this Short Review, we consider this field holds promising prospects for the rational design and development of innovative protocols based on knowledge-driven approaches.

\section{Funding Information}

We thank the CERCA Programme/Generalitat de Catalunya and the Spanish Ministry of Economy, Industry and Competitiveness (MINECO: CTQ2016-79942-P, AIE/FEDER, EU) for the financial support. A. L. M. thanks La Caixa-Severo Ochoa programme for a predoctoral grant.

\section{References}

(1) (a) Schlosser, M. Angew. Chem. Int. Ed. 2006, 45, 5432. (b) Mueller, K.; Faeh, C.; Diederich, F.; Science 2007, 317, 1881. (c) Purser, S.; Moore, P. R.; Swallow, S.; Gouverneur, V. Chem. Soc. Rev. 2008, 37, 320. (d) Ni, C.; Hu, J. Chem. Soc. Rev. 2016, 45, 5441. (e) Orsi, D. L.; Altman, R. A. Chem. Commun. 2017, 53, 7168.

(2) For selected recent reviews on trifluoromethylation, see: (a) Furuya, T.; Kamlet, A. S.; Ritter, T. Nature 2011, 473, 470. (b) Tomashenko, O. A.; Grushin, V. V. Chem. Rev. 2011, 111, 4475. (c) Studer, A. Angew. Chem. Int. Ed. 2012, 51, 8950. (d) GarcíaMonforte, M. A.; Martínez-Salvador, S.; Menjón, B. Eur. J. Inorg. Chem. 2012, 2012, 4945. (e) Ye, Y.; Sanford, M. S. Synlett 2012, 23, 2005. (f) Wu, X.-F.; Neumann, H.; Beller, M. Chem. Asian J. 2012, 7, 1744. (g) Wang, H.; Vicic, D. A. Synlett 2013, 24, 1887. (h) BarataVallejo, S.; Lantaño, B.; Postigo, A. Chem. Eur. J. 2014, 20, 16806. (i) Charpentier, J.; Früh, N.; Togni, A. Chem. Rev. 2015, 115, 650. (j) Liu, X.; Xu, C.; Wang, M.; Liu, Q. Chem. Rev. 2015, 115, 683. (k) Yang, X.; Wu, T.; Phipps, R. J.; Toste, F. D. Chem. Rev. 2015, 115, 826. (l) Alonso, C.; Martínez de Marigorta, E.; Rubiales, G.; Palacios, F. Chem. Rev. 2015, 115, 1847.

(3) (a) McLoughlin, V. C. R.; Thrower, J. U.S. Patent 3408411, 1968. (b) McLoughlin, V. C. R.; Thrower, J. Tetrahedron 1969, 25, 5921.

(4) For representative examples on the synthesis and reactivity of $\mathrm{CuCF}_{3}$ complexes, see: (a) Wiemers, D. M.; Burton, D. J. J. Am. Chem. Soc. 1986, 108, 832. (b) Dubinina, G. G.; Furutachi, H.; Vicic, D. A. J. Am. Chem. Soc. 2008, 130, 8600. (c) Dubinina, G. G.; Ogikubo, J.; Vicic, D. A. Organometallics 2008, 27, 6233. (d) Morimoto, H.; Tsubogo, T.; Litvinas, N. D.; Hartwig, J. F. Angew. Chem. Int. Ed. 2011, 50, 3793. (e) Tomashenko, O. A.; Escudero-Adán, E. C.; Martínez-Belmonte, M.; Grushin, V. V. Angew. Chem. Int. Ed. 2011, 50, 7655. (f) Zanardi, A.; Novikov, M. A.; Martin, E.; Benet-Buchholz, J.; Grushin, V. V. J. Am. Chem. Soc. 2011, 133, 20901. (g) Litvinas, N. D.; Fier, P. S.; Hartwig, J. F. Angew. Chem. Int. Ed. 2012, 51, 536. (h) Novák, P.; Lishchynskyi, A.; Grushin, V. V. J. Am. Chem. Soc. 2012, 134, 16167. (i) Konovalov, A. I.; Lishchynskyi, A.; Grushin, V. V. J. Am. Chem. Soc. 2014, 136, 13410. (j) Lishchynskyi, A.; Berthon, G.; Grushin, V. V. Chem. Commun. 2014, 50, 10237. (k) Mormino, M. G.; 
Fier, P. S.; Hartwig, J. F. Org. Lett. 2014, 16, 1744. (l) Nebra, N.; Grushin, V. V. J. Am. Chem. Soc. 2014, 136, 16998. (m) Morstein, J.; Hou, H.; Cheng, C.; Hartwig, J. F. Angew. Chem. Int. Ed. 2016, 55, 8054.

(5) Martínez de Salinas, S.; Mudarra, A. L.; Odena, C.; Martínez Belmonte, M.; Benet-Buchholz, J.; Maseras, F.; Pérez-Temprano, M. H. Chem. Eur. J. DOI: 10.1002/chem.201900496.

(6) Wiemers, D. M.; Burton, D. J. J. Am. Chem. Soc. 1986, 108, 832 and references cited therein.

(7) (a) Willert-Porada, M. A.; Burton, D. J.; Baenziger, N. C. J. Chem. Soc. Chem. Comm. 1989, 21, 1633. (b) Burton, D. J.; Wiemers, D. M. J. Fluorine Chem. 1985, 29, 359.

(8) Agnes, K.; Movchun, V.; Rodima, T.; Dansauer, T.; Rusanov, E. B. Leito, I.; Kaljurand, I.; Koppel, J.; Pihl, V.; Koppel, I.; Ovsjannikov, G.; Toom, L.; Mishima, M.; Medebielle, M.; Lork, E.; Röschenthaler, G.V.; Koppel, I. A.; Kolomeitsev, A. A. J. Org. Chem. 2008, 73, 2607.

(9) (a) Matsui, K.; Tobita, E.; Ando, M.; Kondo, K. Chem. Lett. 1981, 1719. (b) Carr, G. E.; Chambers, R. D.; Holmes, T. F.; Parker, D. G. J. Chem. Soc., Perkin Trans. I 1988, 921.

(10) Chen, Q.; Wu, S. J. Chem. Soc., Chem. Commun. 1989, 705

(11) Knauber, T.; Arikan, F.; Röschenthaler, G.-V.; Goossen, L. J. Chem. Eur. J. 2011, 17, 2689.

(12) (a) Shono,T.; Ishifune, M.; Okada, T.; Kashimura, S. J. Org. Chem. 1991, 56, 2. (b) Russell, J.; Roques, N. Tetrahedron 1998, 54, 13771.

(13) Folléas, B.; Marek, I.; Normanta, J-F.; Saint-Jalmes, L. Tetrahedron 2000, 56, 275

(14) Lishchynskyi, A.; Novikov, M. A.; Martin, E.; Escudero-Adán, E. C.; Novák, P.; Grushin, V. V. J. Org. Chem. 2013, 78, 11126.

(15) Mudarra, A. L.; Martinez de Salinas, S.; Pérez-Temprano, M. H. Org. Biomol. Chem. 2019, 17, 1655.

(16) (a) Barbosa, H. J.; Collins, E. A.; Hamdouchi, C.; Hembre, E. J.; Hipskind, P. A.; Johnston, R. D.; Lu, J.; Rupp, M. J.; Takakuwa, T.; Thompson, R. C. U. S. Patent 7612067, 2009. (b) Lin, R. W.; Davidson, R. I. Eur. Pat. Appl. EU 307519, 1989. (c) Lin, R. W.; Davidson, R. I. U. S. Patent 4808748, 1989. (d) Davidson, R. I. U. S. Patent 4814480, 1989. (e) Langlois, B. R.; Roques, N. J. Fluorine Chem. 2007, 128, 1318.

(17) a) Li, Y.; Chen, T.; Wang, H.; Zhang, R.; Jin, K.; Wang, X.; Duan, C. Synlett 2011, 1713. b) Schareina, T.; Wu, X.-F.; Zapf, A.; Cotté, A.; Gotta, M.; Beller, M. Top. Catal. 2012, 55, 426. c) Chen, M.; Buchwald, S. L. Angew. Chem., Int. Ed. 2013, 52, 11628. d) Lin, X.; Hou, C.; Li, H.; Weng, Z. Chem. Eur. J. 2016, 22, 2075.

(18) Zhao, G.; Wu, H.; Xiao, Z.; Chen, Q.-Y.; Liu, C. RSC Adv. 2016, 6, 50250 .

(19) (a) MacNeil, J. G. Jr.; Burton, D. J. J. Fluorine Chem., 1991, 55, 225. (b) Duan, J-X.; Su, D-B.; Wu, J-P.; Chen, Q-Y.J. Fluorine Chem., 1994 66, 167.

(20) Prakash, G. K. S.; Hu, J.; Olah, G. A. Org. Lett. 2003, 5, 3253.

(21) Serizawa, H.; Aikawa, K.; Mikami, K. Chem. Eur. J. 2013, 19, 17692

(22) Li, X.; Zhao, J.; Zhang, L.; Hu, M.; Wang, L.; Hu, J. Org. Lett. 2015, 17, 298.

(23) (a) Burton, D. J.; Yang, Z. Y. Tetrahedron 1992, 48, 189. (b) Morrison, J. A. Adv. Organomet. Chem. 1993, 35, 211.

(24) Kondratenko, N. V.; Vechirko, E. P.; Yagupolskii, L. M. Synthesis 1980, 932.
(25) Burton, D. J.; Wiemers, D. M. J. Am. Chem. Soc. 1985, 107, 5014

(26) (a) Krause, L. J.; Morrison, J. A. J. Am. Chem. Soc. 1981,103, 2995. (b) Krause, L. J.; Morrison, J. A. J. Chem. Soc., Chem. Commun. 1981, 1282. (c) Nair, H. K.; Morrison, J. A. Inorg. Chem. 1989, 28, 2816. (d) Galiotos, J. K.; Morrison, J. A. Organometallics 2000, 19, 2603.

(27) Popov, I.; Lindeman, S.; Daugulis, 0. J. Am. Chem. Soc. 2011, 133, 9286.

(28) Nakamura, Y.; Fujiu, M.; Murase, T.; Itoh, Y.; Serizawa, H.; Aikawa, K.; Mikami, K. Beilstein J. Org. Chem. 2013, 9, 2404.

(29) Aikawa, K.; Nakamura, Y.; Yokota, Y.; Toya, W.; Mikami, K. Chem. Eur. J. 2015, 21, 96

(30) Urata, H.; Fuchikami, T. Tetrahedron 1991, 32, 91.

(31) Oishi, M.; Kondo, H.; Amii, H. Chem. Commun., 2009, 1909.

(32) a) Mitsudera, H.; Li, C.-J. Tetrahedron Lett. 2011, 52, 1898; b) Xu, J.; Xiao, B.; Xie, C.-Q.; Luo, D.-F.; Liu, L.; Fu, Y. Angew. Chem. Int. Ed. 2012, 124, 12719; c) Gonda, Z.; Kovács, S.; Wéber, C.; Gáti, T.; Mészáros, A.; Kotschy, A.; Novák, Z. Org. Lett. 2014, 16, 4268.

(33) Hu, M.; Ni, C.; Hu, J. J. Am. Chem. Soc. 2012, 134, 15257.

(34) Chu, L.; Qing, F-L. Acc. Chem. Res. 2014, 47, 1513.

(35) (a) Chu, L.; Qing, F-L. J. Am. Chem. Soc. 2010, 132, 7262. (b) Chu, L.; Qing, F.-L. Org. Lett., 2010, 12, 5060.

(36) Jiang, X.; Chu, L.; Qing, F-L.J. Org. Chem. 2012, 77, 1251.

(37) Jover, J.; Maseras, F. Chem. Commun., 2013, 49, 10486.

(38) Weske, S; Schoop, R.; Koszinowski, K. Chem. Eur. J. 2016, 22, 11310.

(39) Sanhueza, I. A.; Nielsen, M. C.; Ottiger, M.; Schoenebeck, F. Helv. Chim. Acta 2012, 95, 2231.

(40) Khan, B. A.; Buba, A. E.; Gooßen, L. J. Chem. Eur. J. 2012, 18, 1577.

(41) Geri, J. B.; Wolfe, M. M. W.; Szymczak, N. K. Angew. Chem. Int. Ed. 2018, 57, 1381.

(42) (a) Chan, D. M. T.; Monaco, K. L.; Wang, R.-P.; Winters, M. P. Tetrahedron 1998, 39, 2933; (b) Lam, P. Y. S.; Clark, C. G.; Saubern, S.; Adams, J.; Winters, M. P.; Chan, D. M. T.; Combs, A. Tetrahedron 1998, 39, 2941.

(43) https://www.sigmaaldrich.com/catalog/product/aldrich/77769 2?lang=es\&region $=\mathrm{ES}$

(44) Usui, Y.; Noma, J.; Hirano, M.; Komiya, S. Inorg. Chim. Acta 2000, 309, 151.

(45) Kaplan, P. T.; Loyd, J. A.; Chin, M. T.; Vicic, D. A. Beilstein J. Org. Chem. 2017, 13, 2297.

\section{Biosketches}




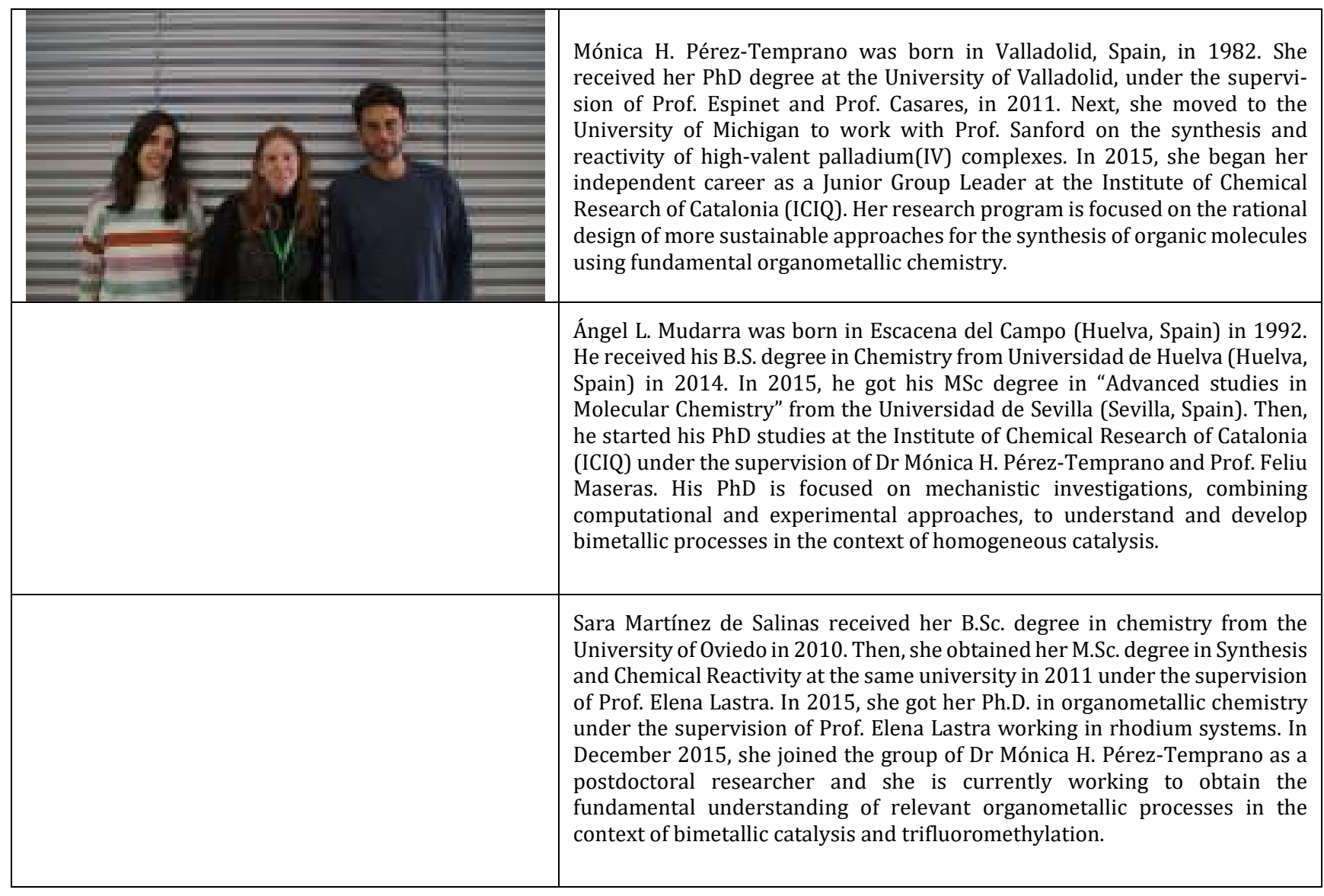

